\title{
SENI HIAS WUWUNG MAYONG JEPARA JAWA TENGAH KAJIAN BENTUK, MAKNA, DAN FUNGSI
}

\author{
Oleh: Arif Suharson
}

\begin{abstract}
Javanese culture derives from the intellectual, emotional, and physical process in Javanese environment. This process goes on to keep up with the constant changes in the environment. This process has resulted in such artistic products as decorative roof top of wuwung in Mayong Jepara Central Java. The wuwung has been aesthetically put on top of Javanese traditional houses precisely above the blandar penuwun. This roof top serves the function as the cover to keep water and dust from entering the house. This such kind of wuwung is characteristically decorated with glass mozaik and is therefore uniquely different from that in other regions.

This analysis is attempting to identify and prove qualitative explanation. Accordingly this study employs qualitative method to avoid mathematic calculation. It is so because what matters is the value of particularly specific and unique objects which contain meaningful action. The study deals with visual art, particularly ceramic craft of clay. It is expected that there will be sustainable benefits to reserve local genius in the national culture. The art work of decorative wuwung from Mayong Lor Jepara Central Java is characteristically clear and can be classified by time, technique of making, decorative technique, material, and meaning.

Results of thestudy suggested that wuwungan wayang in Mayong Central Java which is familiar in Javanese society clearly represents such good characters or heroic figures. For the Javanese people who already held particular beliefs such animism and dynamism long before the introduction of such religons as Hindu, Budha, and Islam, put a historical background in the development of meaningful symbols. Home decoration implies more than physical activities; rather it implies praying and expectation represented by the decorative wuwung produced in Mayong Jepara with its aesthetic beautiful mozaik of glass.
\end{abstract}

Keywords: decorative art, wuwung, glass mozaik, Mayong Jepara

\section{ABSTRAK}

Kebudayaan Jawa lahir dari olah pikir, rasa, dan karsa pada lingkungan hidup masyarakat etnis Jawa dalam kurun waktu yang terus berproses dalam menghadapi perubahan zaman yang ada. Dari kebudayaan Jawa itu, lahirlah berbagai produk sebagai hasil untuk pemenuhan kebutuhan dari olah pikir, rasa, dan karsa tersebut. Salah satunya adalah seni hias wuwung hasil kreasi masyarakat Mayong Jepara Jawa Tengah yang menghiasi atap rumah adat tradisional Jawa. Wuwung hias dipasang pada atap rumah paling atas di atas blandar penuwun yang berfungsi sebagai penutup genteng paling atas dan berfungsi menahan debu atau air agar tidak masuk ke dalam rumah dengan ornamentasi pecahan beling yang memiliki ciri khas yang tidak dimiliki oleh daerah lain.

*) Arif Suharson (arifkeramos@yahoo.com), Staf Pengajar Program studi Kriya Seni, Jurusan Kriya, Fakultas Seni Rupa, Institut Seni Indonesia Yogyakarta. 
Kajian ini berusaha mencari dan memberikan penjelasan secara kualitatif, sehingga metode yang digunakan adalah kualitatif. Metode ini menghindari perhitungan matematis, karena yang dicari adalah value 'nilai' yang muncul dari objek kajian yang bersifat khusus, bahkan sangat spesifik, unik dan selalu mengandung meaning full action. Penelitian ini sebagai salah satu telaah lingkup bidang ilmu seni rupa, khususnya seni kriya keramik yang memanfaatkan material tanah atau lempung. Hal ini akan memiliki dampak yang berkelanjutan, sehingga kekayaan tradisi lokal akan tetap berjalan sebagai ciri local genius yang memperkaya khasanah budaya bangsa. Produk seni wuwung hias dari Mayong Lor Jepara Jawa Tengah yang dijadikan obyek penelitian, memiliki ciri khas dan sifat yang dapat diidentifikasi secara jelas, dan dapat diklasifikasi menurut waktu, teknik pembuatan, teknik seni hias, dan bahan material yang digunakan serta makna yang terkandung dari penciptaan seni hias wuwungan tersebut.

Mengambil inti sari dari hasil kajian penelitian yang telah dilakukan bahwa sebutan wuwungan wayang yang akrab dalam kehidupan masyarakat Jawa, maka penafsiran bentukbentuk seni hias wuwung Mayong Jepara Jawa Tengah jelas mengarah pada tokoh-tokoh kebaikan atau tokoh-tokoh pahlawan dalam membela kebenaran. Keyakinan masyarakat Jawa yang sudah memiliki agama sebelum agama-agama besar datang seperti Hindu, Budha, dan Islam, tentu keberadaan kepercayaan animisme dan dinamisme menjadi latar belakang sejarah yang kuat dalam menggambarkan simbol yang mempunyai arti. Keberadaan menghias rumah tentu tidak hanya sekedar menghias, tetapi sekaligus merupakan doa dan harapan yang ingin dicapai yang terwujud pada seni hias wuwung Mayong Jepara dengan ciri khusus ornamen pecahan beling yang indah.

Kata Kunci: Seni hias, wuwung, pecahan beling, Mayong Jepara

\section{PENDAHULUAN}

Berbicara mengenai bentuk dan fungsi wuwung hias bagi masyarakat Jawa, selain untuk menambah keindahan atap rumah, juga memiliki nilai filosofis yang berhubungan dengan makna. Pengertian wuwung dalam Kamus Bahasa Jawa adalah gendeng (atep) sing ditrap ing tumpukaning payon sing dhuwur (soko dhuwure molo) (Widada dkk., 2001:858). Artinya wuwung merupakan bubungan rumah, yaitu bagian dari atas rumah tradisional Jawa yang berfungsi sebagai tutup pada atap rumah agar tidak terkena air hujan ataupun debu yang masuk lewat atap.
Kajian ini menekankan pada seni hias wuwung yang terdapat pada atap rumah adat Jawa yang dibuat oleh pengrajin gendeng di Mayong Lor Jepara Jawa Tengah. Seni hias wuwung terlihat berbeda dengan seni hias wuwung biasa yang dibuat oleh pengrajin wuwung di wilayah sentra Kasongan, Godean, dan Kebumen. Wuwung ini dibuat dengan nuansa pecahan beling/piring yang terlihat hidup dan bercahaya. Visualisasi bentuk wuwung hias yang bervariatif memunculkan suatu pertanyaan dan sesuatu alasan mengapa wuwung hias di daerah Mayong Lor Jepara berbeda 
bentuk visualisasinya. Secara keseluruhan, bentuk seni hias wuwung ada dua jenis menurut bahan dasarnya, yaitu gerabah dan logam/seng. Seni hias wuwung gerabah sudah mulai diterapkan lebih dahulu dari pada seng pada bangunan rumah tempat tinggal masyarakat Jawa. Bahkan juga pernah dibuat seni hias wuwung serupa dari bahan kayu dan batu. Dalam penelitian ini akan dibahas secara khusus seni hias wuwung dari bahan tanah liat atau gerabah.

Pengrajin wuwung hias di Mayong Jepara Jawa Tengah pada dasarnya memiliki kebiasaan, yang pada hakekatnya meniru apa yang telah diwarisi secara turun tumurun, dengan kata lain mengulang produk yang sama. Wuwung hias yang dibuat adalah suatu karya seni yang unik dan karakteristik yang di dalamnya mengandung muatan nilai-nilai yang mantap dan mendalam menyangkut nilai estetik, simbolik, filosofis, dan fungsional. Penampilan visualisasi bentuk wuwung hias dengan pecahan piring/beling bukan hanya sebagai unsur seni hias semata yang ditunjang dengan bentuk, gaya, struktur seni hias yang tidak biasa. Melihat visualisasi tersebut perlu adanya kajian ilmiah dengan melakukan penelitian untuk mengetahui apa maksud dan tujuan dari visualisasi bentuk wuwung tersebut. Kajian ilmiah ini juga akan mengetahui makna dan fungsi seni hias wuwung Mayong Jepara yang berbeda dengan wuwung yang biasa dibuat di daerah lain dengan ornamentasi pecahan piring yang indah.

\section{PEMBAHASAN}

Masyarakat pengrajin seni hias wuwung gerabah Mayong Jepara selain memproduksi seni hias wuwung gerabah, para pengrajin di Desa Mayong Lor juga memproduksi bendabenda fungsional lain seperti perabotan rumah tangga gerabah dan kebutuhan produk gerabah untuk kegiatan upacara tradisional. Produk fungsional tersebut dijual dengan finishing merahan atau asli bakaran, seperti produk kuali, kendi, wajan, anglo, tempat ari-ari, cobek, dan celengan. Saat ini banyak pengrajin yang terjun membuat genteng cetak press yang dinilai lebih praktis, mudah, cepat, dan tidak rumit dalam proses pembuatannya. Selain itu genteng press lebih cepat laku dibanding dengan membuat produk gerabah khususnya membuat seni hias wuwung yang berornamen pecahan beling. Sehingga para pengrajin seni hias wuwung Mayong Lor yang berornamenkan pecahan beling mulai tersisih dan perlu mendapatkan perhatian kita bersama.

Seni hias wuwung Mayong Jepara sering disebut sebagai wuwung wayang, wuwung jengger, wuwung Kudus, dan wuwung ukiran. Disebut wuwung wayang karena visualisasi wuwung yang diproduksi oleh 
pengrajin Mayong Jepara bentuknya menyerupai bentuk gunungan yang biasa dilihat dalam pertunjukan wayang kulit. Masyarakat umum juga mengatakan wuwung jengger karena visualisasinya menyerupai jengger ayam jago yang biasanya tumbuh di atas kepala ayam jago dewasa. Banyak juga yang mengatakan wuwung Kudus dimana aplikasi seni hias wuwung ini banyak digunakan masyarakat Kudus untuk menghias atap rumah mereka (joglo pencu). Karena banyaknya konsumen masyarakat dari wilayah Kudus yang sering mengaplikasikan seni hias wuwung Mayong Jepara ini, maka muncullah sebutan wuwung Kudus, padahal masyarakat Kudus tidak ada yang memproduksi seni hias atap rumah Jawa ini.

Akan tetapi kenyataan ini tidak bisa dihindarkan karena proses sejarah yang telah menjadikan rumah tradisional Kudus sebagai dasar yang kuat, sehingga menyebut seni hias wuwung Mayong Jepara menjadi wuwung Kudus. Bila dilacak balik, persamaan itu merupakan indikasi, bahwa raja-raja Mataram dalam membangun keraton, pada permulaan abad ke-17 mencontoh bentuk dan susunan bangunan keraton Demak atau Pajang yang dibangun pada abad ke-16, menurut pola dasar keraton kerajaan Majapahit abad ke-15 atau ke-14. Seni bangunan tradisional untuk para elite bangsawan Demak, pada masa awal pertumbuhan Islam di pesisir utara
Jawa, masih dapat dinikmati hingga sekarang, diantaranya rumah tradisional Kudus Demak, yang pada mulanya berperan sebagai pusat pertumbuhan dan perkembangan Islam di Jawa memberikan sumbangan besar bagi perkembangan kehidupan sosial, termasuk berkembangnya kesenian bercorak Islam (Gustami, 2007:175).

Begitu pula dengan seni hias wuwung Mayong Lor Jepara, sebagai produk budaya yang memiliki ciri khas sebagai salah satu produk budaya Indonesia jangan dilihat sebagai produk tradisi yang tidak bisa berbicara pada era modern seperti zaman sekarang. Tinggal bagaimana sikap dan pola pikir masyarakat kita apakah masih memandang hasil produk seni hias wuwung Mayong Lor Jepara yang berornamen pecahan beling ini sebagai produk tradisi yang kuno yang sudah tidak relevan lagi dengan bangunan rumah masyarakat modern. Atau kita bangga dengan sebutan modern tetapi lupa akan identitas dan jati diri masyarakat Jawa yang salah satunya dengan meninggalkan seni hias wuwung tidak untuk menghias atap rumah kita.

Kajian tentang seni hias wuwung gerabah Mayong Jepara memerlukan suatu landasan teori yang dapat menunjang terselenggaranya penelitian sebagaimana yang diharapkan. Keberadaan seni hias wuwung gerabah di tengah-tengah masyarakat yang situasi dan kondisi 
perkembangannya mengalami pasang surut, tidak dapat lepas dari faktor sosial dan budaya masyarakat pendukungnya. Dalam penelitian ini dipakai sebagai teori utama adalah teori dari Edmund Burke Feldman. Edmund Burke Feldman dalam bukunya yang berjudul Art as Image and Idea mengemukakan teori dalam karya seni melalui beberapa aspek, yaitu: the functions of art (personal, social, physical), the styles of art (objective accuracy, formal order, emotion, fantasy), the structure of art (grammar, design, aesthetics), the interaction of medium and meaning (painting, sculpture, architecture), (Feldman, 1967:6-306). Dalam penelitian ini pendekatan estetik merupakan pendekatan utama dengan didukung beberapa pendekatan lainnya, seperti pendekatan sejarah, pendekatan arsitektur, dan semiotika.

Berdasarkan pendapat Feldman tersebut dapat diinterpretasikan bahwa fungsi personal berkaitan dengan seni sebagai media untuk mengungkapkan ekspresi pribadi seniman dalam wujud karya seni; fungsi sosial adalah perwujudan seni yang terkait dengan kondisi sosial. Dalam pendapat yang sama dijelaskan bahwa karya seni menunjukkan fungsi sosial apabila: 1) karya seni itu cenderung mempengaruhi perilaku kolektif orang banyak, 2) karya itu diciptakan untuk dilihat atau dipakai khususnya dalam situasi-situasi umum, 3) karya seni itu mengekpresikan atau menjelaskan aspek-aspek tentang eksistensi sosial. Fungsi fisik berkaitan dengan karya seni yang secara fisik memiliki kegunaan praktis seperti seni hias wuwung Mayong Jepara. Lebih jelas disebutkan Feldman bahwa fungsi fisik seni ialah suatu ciptaan objek-objek yang dapat berfungsi sebagai wadah dan alat (Feldman, terjemahan SP. Gustami, bagian satu, 1991: 4-127).

Berdasarkan analisis gaya seni, Feldman mengklasifikasikan karya seni menurut waktu, daerah, wujud, teknik dan subject matter. Analisis ini akan dipergunakan untuk mengurai gaya seni hias wuwung gerabah Desa Mayong Lor Jepara termasuk untuk menjelaskan media dan teknik yang merupakan salah satu bagian dalam pembahasan penelitian ini. Lebih lanjut dijelaskan media adalah suatu penggunaan karakteristik dari bahanbahan khusus untuk suatu tujuan artistik. Menurut Feldman untuk mengkaji struktur seni diurut dari unsur seni rupa dan pengorganisasian elemen seni, termasuk kontribusi penikmat terhadap karya seni. Seni Hias Wuwung Gerabah Mayong Lor Jepara secara konstekstual terkait dengan sejarah, terutama dalam hubungannya dengan faktor-faktor yang mempengaruhi pertumbuhan dan perubahannya.

Berkaitan dengan pendekatan di atas, dalam mengkaji bentuk, fungsi, struktur, gaya, media dan teknik, digunakan pendekatan estetis. Dapat 
dilihat bahwa seni hias wuwung Mayong Lor Jepara memiliki 4 bagian penting yang harus diketahui terekam dalam foto peneliti pada tahun 2015. Empat bagian penting itu adalah:

1. Seni hias wuwung bagian atas diposisi tengah-tengah disebut sebagai wuwung rojo
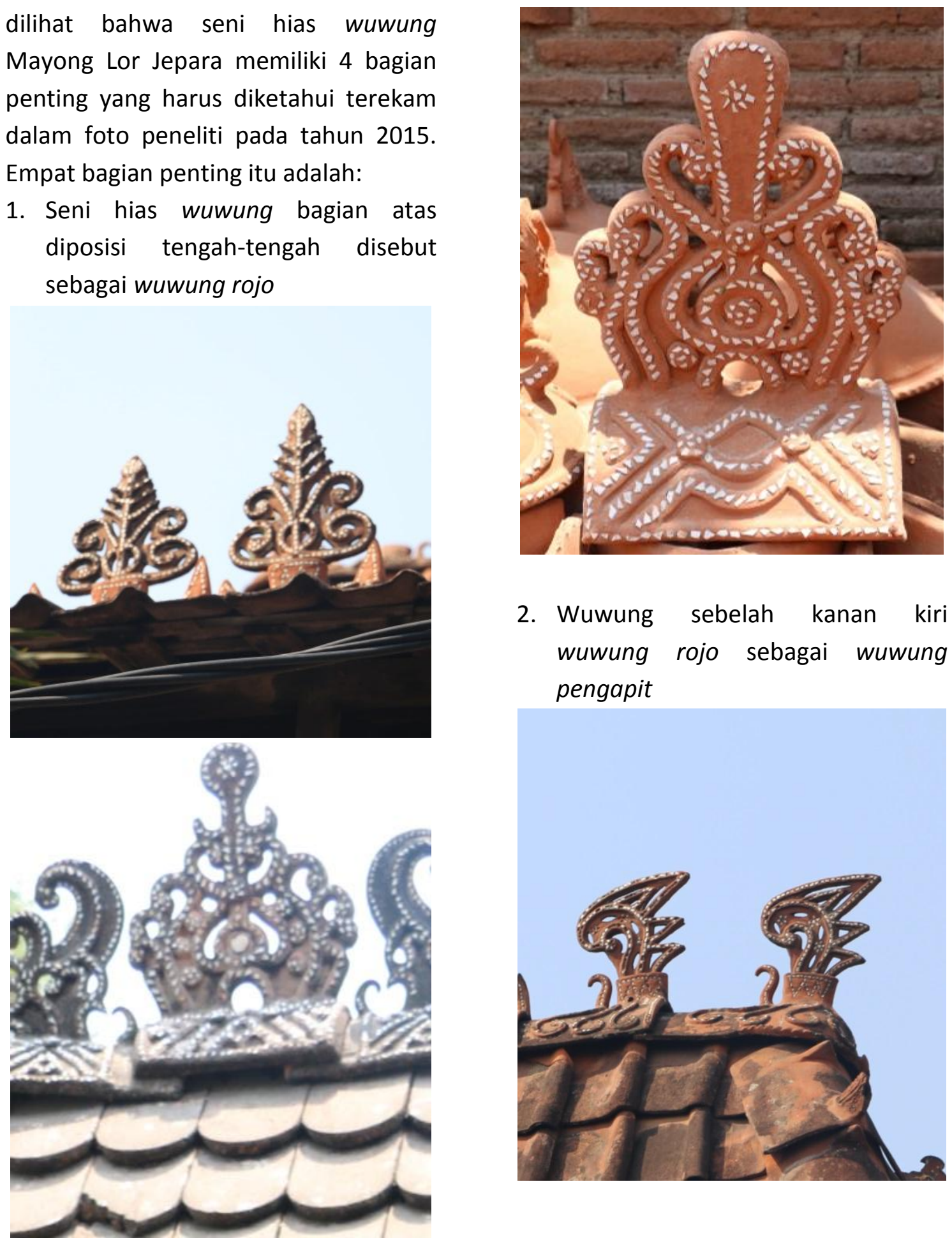

2. Wuwung sebelah kanan kiri wuwung rojo sebagai wuwung pengapit

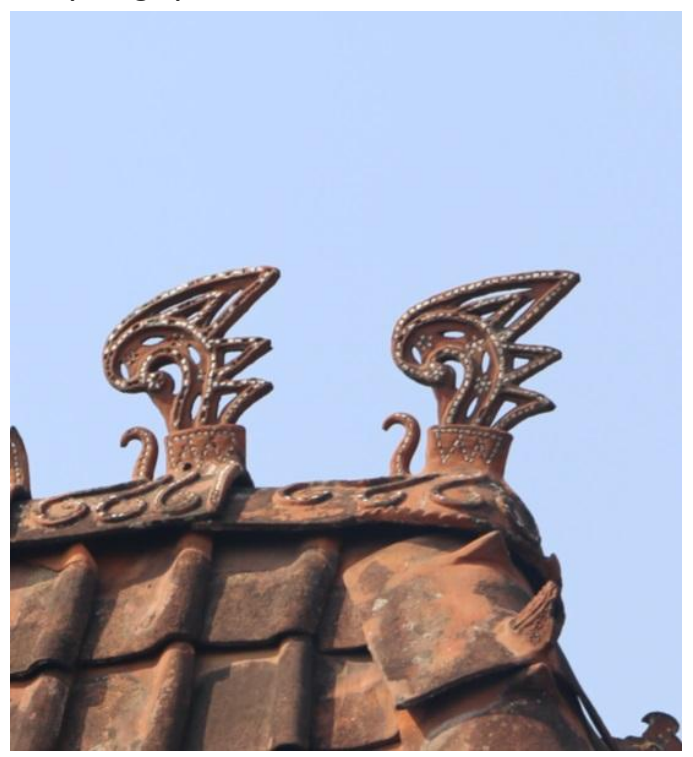




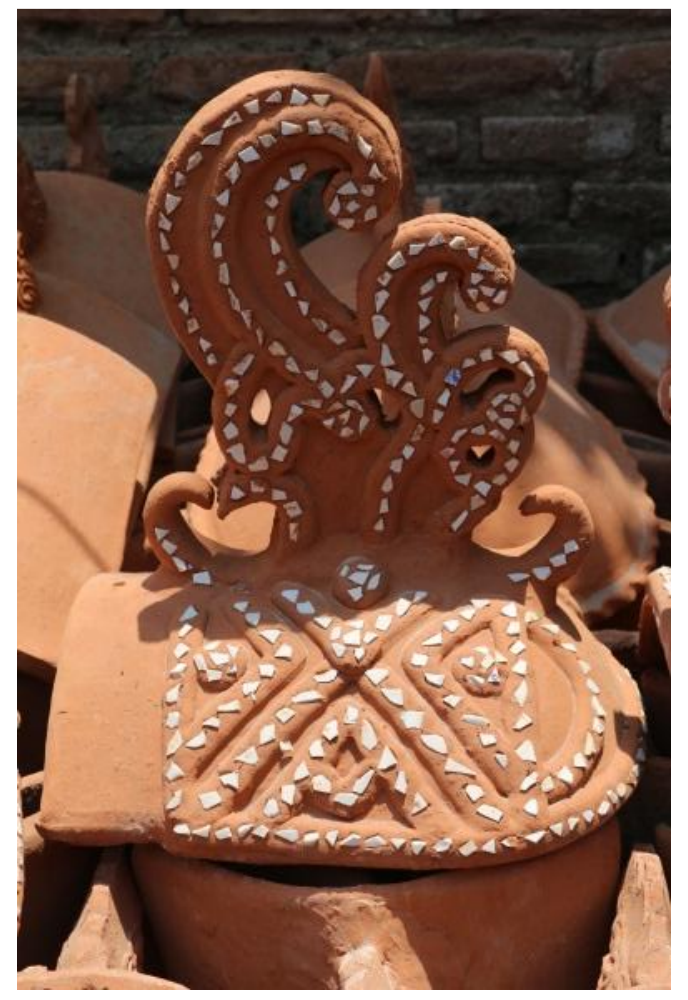

3. Seni hias wuwung bagian atas diposisi paling ujung/sudut kanan dan kiri disebut sebagai wuwung bulusan

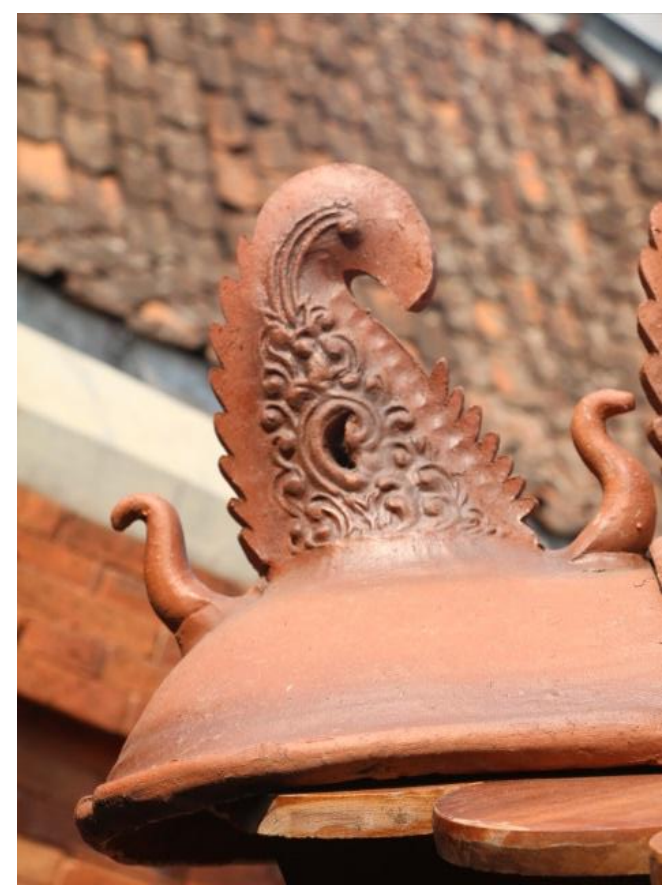

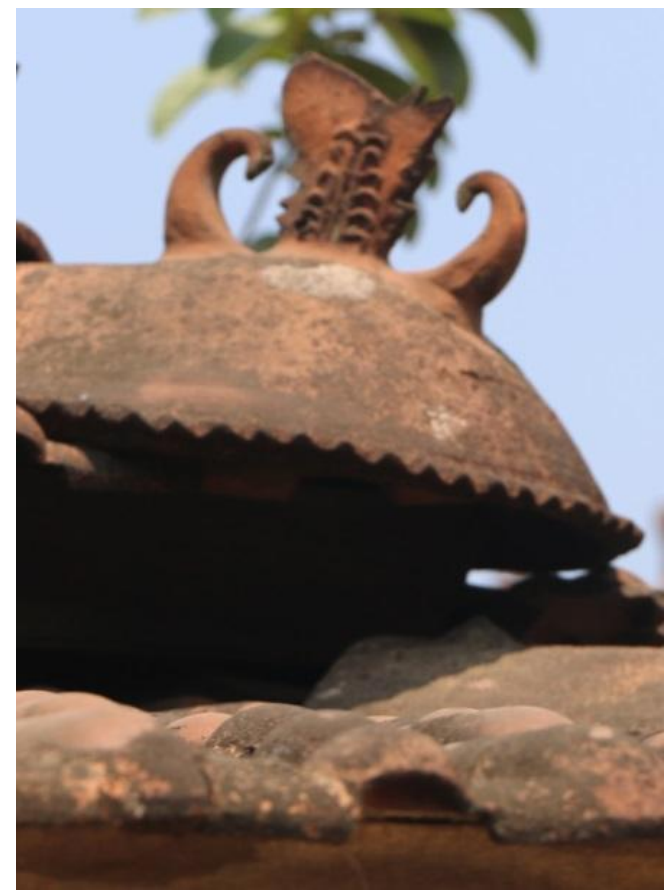

4. Seni hias wuwung bagian pinggir ke bawah disebut sebagai wuwung jengger.

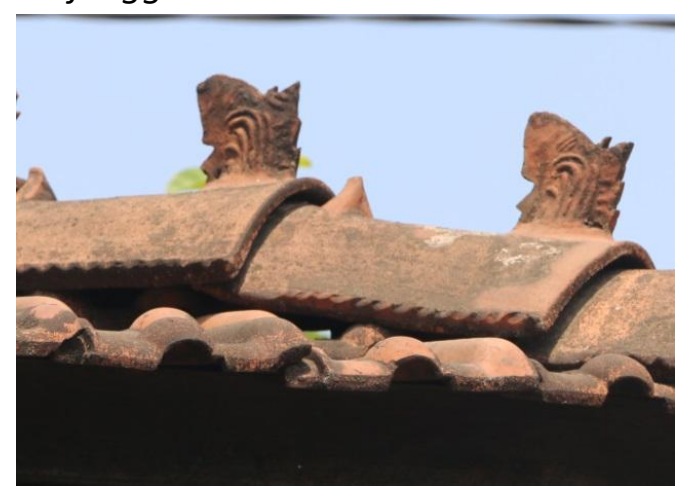




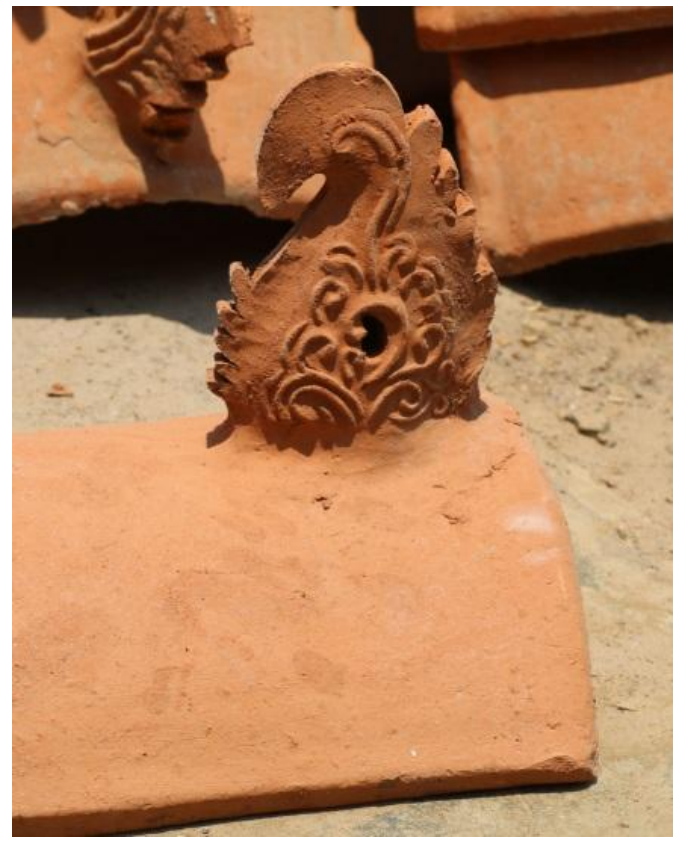

Melihat posisi seni hias wuwung yang berada di atas atau bagian atap yang paling atas yang tertata berderet dan saling berhadapan dengan posisi wuwung rojo yang berada di tengahtengah seperti menggambarkan posisi pentas wayang kulit. Sehingga tak jarang seni hias wuwung Mayong Jepara ini disebut sebagai wuwung wayang. Posisi wayang yang saling berhadapan kanan dan kiri digambarkan sebagai tokoh-tokoh dalam pentas wayang kulit dan posisi tengah yang disebut wuwung rojo bisa disebut sebagai gunungan wayangnya. Sedangkan wuwung jengger memang merupakan stilisasi dari bentuk kepala ayam jantan yang diambil pada bagian paling atas yang biasanya berwarna merah yang disebut jengger. Jengger ini ditempatkan pada bagian atap genteng diposisikan di atas blandar yang menopang blandar penuwun.
Pemasangan wuwung jengger pada blandar yang menopang blandar penuwun di 4 penjuru arah.

Seni wayang yang hidup dalam sendi-sendi kehidupan masyarakat Jawa telah menyatu juga dalam kehidupan estetis yang tervisualisasi dalam bentuk-bentuk seni hias seperti seni hias wuwung untuk menghias tempat tinggal yaitu rumah. Inspirasi bentuk mahkutho, gelung supit urang, dan gunungan menjadi ide dasar penciptaan seni hias rumah masyarakat Mayong Jepara dalam menciptakan seni hias wuwung tempat tinggal tersebut. Penambahan pecahan beling yang mengikuti alur ornamentasi pada seni hias wuwung merupakan wujud ekspresi untuk membuat seni hias tersebut lebih memiliki kesan indah dan agung. Jika melihat struktur wuwung Mayong Jepara ini terdiri dari 2 bagian yaitu; 1) bagian kepala wuwung yang berisi ukiran dan 2) bagian tubuh wuwung yang menopang ukiran. Bagian-bagian seni hias dengan berbagai ornamen wuwung Mayong Jepara yang telah dijelaskan dengan gambar di atas telah menunjukkan 2 bagian utama yang dalam proses produksinya sebelum digabungkan dibuat terpisah. Pola seni hias dibuat simetris dan biasanya ada pola untuk membuat kemiripan motifnya, tetapi ada yang dibuat langsung tanpa menggunakan pola dengan langsung membuat dengan tangan terampil para pengrajinnya. 
Bentuk seni hias wuwung Mayong Jepara memang tidak terlepas dari bagian-bagian kebudayaan sebelumnya. Pengaruh agama Hindu juga masih melekat dengan bentuk atap tumpang yang menyerupai bentuk gunung/Meru yang kemudian dikembangkan dengan cara membuat stilisasi yang mengacu juga pada seni ukir yang berkembang di Jepara. Ide ukiran kemungkinan juga mengacu pada bentuk ukiran bangunan makam yang berada di belakang menara Kudus. Pengambilan model atap tumpang itu tidak dapat dilepaskan dari cita-cita estetik Wali Songo yang cemerlang berdasarkan pendekatan psikologi orang Jawa. Dalam ingatan orang Jawa, masih terbayang kebesaran dan kemegahan Majapahit yang Hinduistis. Bentuk bangunan Joglo, tipologi istana Majapahit dengan atap mirip bentuk meru, adalah model atap yang dimanfaatkan untuk pembangunan masjid dan makam.

\section{Bagian seni hias wuwung Mayong Jepara}

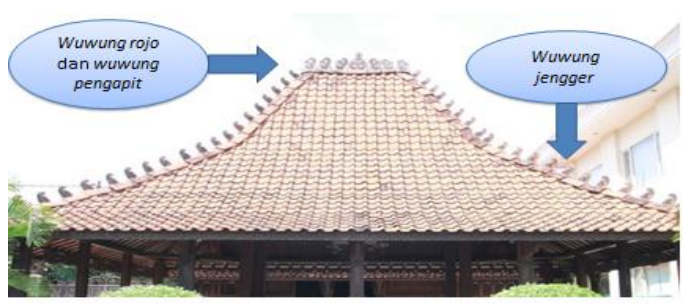

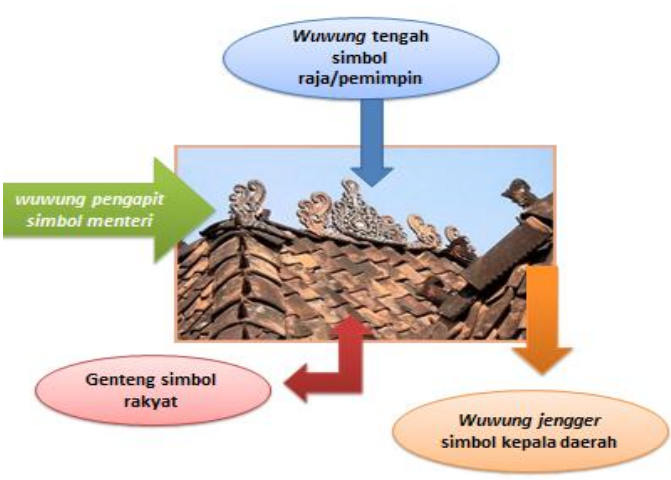

Menurut penuturan bapak Ridwan sebagai salah seorang tokoh yang masih mengerti seluk-beluk seni hias wuwung Mayong Jepara mengatakan bahwa wuwung ukir yang diberi pecahan beling/piring ini memang memiliki tujuan dalam penciptaannya. Yaitu bagian-bagian bentuk seni hias wuwung tersebut diibaratkan sebagai tokoh atau simbolisasi dari suatu bentuk negara atau pemerintahan. Dimana suatu pemerintahan membutuhkan seorang pemimpin, wakil pemimpin, para menteri, kepala-kepala pemerintah, dan rakyat. Rumah tradisional Jawa yang dalam hal ini masyarakat umum di Jepara banyak menggunakan bentuk rumah limasan diibaratkan suatu negara atau pemerinta itu sendiri. Bentuk wuwung yang posisinya di tengah-tengah disebut sebagai raja atau pemimpin suatu negara. Disamping raja ada wuwung pengapit yang disebut sebagai wakil-wakil kepercayaa raja untuk membantu terlaksananya titah sang raja atau kepanjangan tangan dari tugas sang raja. Dan bentuk wuwung jengger yang 
disebut sebagai kepala-kepala yang memerintah dibagian-bagian daerah wilayah suatu negara. Dan genteng disebut suatu simbol dari rakyat.

Atribut pecahan piring juga hanya dipergunakan pada bagian atap yang berada di tengah saja yaitu pada bagian wuwung rojo wuwung dan pengapit. Sedangkan pada bagian wuwung jengger yang menutup pada bagian atap samping kanan dan kiri tidak memakai pecahan piring/beling. Ini menyimbulkan juga bahwa seorang pemimpin yang di atas menunjukkan golongan/kasta yang mempunyai kepandaian tertentu atau ilmu yang linuwih dibanding dengan kepala daerah bahkan rakyat. Simbol pecahan piring/beling yang melekat pada wuwung di atas atap rumah merupakan simbol sebuah mahkota yang bertahtakan berlian layaknya mahkota raja. Pada umumnya, raja yang bertahta di Jawa mengenakan mahkota berbentuk kuluk atau songkok. Seperti diketahui, raja putri di negeri Belanda umumnya menggunakan Crown sebagai mahkota raja yang berbentuk perhiasan kepala berbentuk melengkung. Pengaruh Belanda ini juga diacu oleh keraton dalam menciptakan sebuah mahkota bagi raja yang bertahtakan berlian, emas, perak atau batu mulia yang gemerlap. Ini juga diadopsi untuk menciptakan atribut-atribut bagi wakil raja dan orang-orang terdepan bahkan keluarga raja sebagai simbolisasi bangsawan.
Menurut Hermanu, seni hias wuwung Mayong Jepara yang ukirannya ditambah dengan pecahan beling/piring juga memiliki fungsi aktif yang luar biasa. Suatu pemikiran orang Jawa yang juga sangat berlian di masa itu. Pecahan piring/beling syarat dengan nilai estetika keindahan yang meniru indahnya mahkota raja. Bahkan memiliki fungsi aktif sebagai penangkal petir rumah untuk melindungi rumah darai bahaya petir. Daerah pesisir utara terutama Kudus, Demak, dan Jepara mempunyai bahaya petir yang tinggi, sehingga konsep pecahan beling/piring sebagai tolak bala dari bahaya petir. Ada semacam legenda atau gugon tuhon menurut orang Jawa di wilayah Pati dan sekitarnya yang mengatakan bahwa wuwungan itu di masa jaman dahulu dibuat sebagai penangkal petir, karena wilayah Pati dan Kudus terkenal sebagai daerah yang mempunyai frekuensi petir tertinggi di Jawa, maka dibuatlah wuwungan yang ditempeli pecahan piring porselen sebagai upaya penangkal petir (Hermanu, 2004:12).

\section{Kajian Makna Wuwung Mayong Jepara Dalam Persepsi Budaya Jawa}

Kehidupan orang Jawa dengan aneka ragam budayanya memiliki kecenderungan untuk menyampaikan sesuatu secara tidak langsung dengan melalui unggah-ungguh, simbol, perumpamaan atau sanepo/sanepan, juga bisa berupa sindiran yang lugas 
bahkan kehidupan orang Jawa yang berupa norma yang tidak tertulis coba diungkap. Bahasa atau norma itu sering dilantunkan dalam bahasa wayang sebagai media yang efektif untuk menyampaikan pesan, ajakan, pepiling, atau tujuan tertentu. Gaya penyampaian seperti tersebut di atas sangat mengakar dalam kehidupan Jawa yang tercermin dalam kehidupan berbudaya (Budiono Herusatoto, 2001). Hal ini juga ditegaskan oleh Arya Ronald dalam menggambarkan kebudayaan Jawa terutama dalam hal arsitektur rumah tradisional Jawa, yang mengungkapkan bagaimana konsep, cara membangun wujud nyata rumah tradisional Jawa. Kebudayaan dalam kehidupan orang Jawa pada dasarnya dinyatakan dalam empat areal atau lingkup keyakinan yaitu kepercayaan, ikatan sosial, ekspresi pribadi, permasalahan atas makna. Arsitektur rumah tradisioanal Jawa dapat dilihat dari aspek arsitek dan budaya, nilai mistik atau simboliknya, sampai pada pelestraian rumah Jawa yang memuat identitas budaya di tengah-tengah arus modernisasi yang begitu dahsyat sampai sekarang (Arya Ronald, 2005).

Orang Jawa menganggap bahwa rumah sebagai tempat tinggal itu sama dengan pribadi yang memilikinya. Kata omah yang berarti rumah tempat tinggal, mempunyai arti penting yang berhubungan erat dengan kehidupan oarng Jawa. Kehidupan orang Jawa termaktub dalam tiga ungkapan kata yaitu: sandang, pangan, dan papan yang artinya pakaian, makan, dan tempat tinggal (H.J. Wibowo, 1987:82). Untuk itu orang Jawa dalam mendirikan rumah sebagai tempat tinggal tidak asal saja mendirikan, akan tetapi perlu dipikirkan hal-hal lain untuk memperoleh ketentraman lahir dan batin. Dalam kehidupan orang Jawa nilai-nilai psikologis dan spiritual sangat menjadi landasan utama untuk mencapai tujuan kebahagian tersebut.

Secara umum bentuk rumah tradisional di wilayah Jepara dan Kudus berbentuk limasan, kampung, dan joglo dimana menggunakan bentuk hiasan wuwung dari Mayong Jepara. Menurut Suwarno, sebagai bentuk hiasan dapat dikategorikan dalam dua macam yaitu wuwungan wayang dan wuwungan kayon/gunungan. Sebuah wuwung berbentuk gunungan diletakkan di tengah-tengah di atas wuwungan rumah. Selanjutnya ke arah samping kanan gunungan atau kayon, diletakkan secara berderet wuwung-wuwung berbentuk gelung wayang dengan menghadap ke kanan. Sebaliknya ke arah kiri dipasang wuwung berbentuk gelung wayang menghadap ke kiri, sehingga antara wuwung berbentuk hiasan gelung wayang disebelah kanan gunungan dan wuwung berbentuk hiasan gelung wayang di sebelah kiri gunungan tampak saling bertolak belakang. Penataan keletakan seperti itulah kemungkinan yang menyebabkan penduduk setempat menyebutnya 
sebagai hiasan wayangan, karena susunan wuwung yang demikian itu identik dengan susunan wayang yang dijejer dalam kelir sebelum pertunjukan yang sebenarnya dimulai (Suwarno, 2007:193).

Bentuk gunungan dalam dunia pewayangan sudah jelas yaitu salah satu wayang yang bentuknya menyerupai gunung dengan di dalamnya terdapat lukisan dunia flora dan fauna. Dalam pentas pewayangan kayon atau gunungan digunakan untuk membuka suatu pertunjukan wayang yang sering disebut jejer, pada saat membuka adegan gara-gara, pergantian setting cerita, episode, dan saat tancep kayon ketika pertunjukan sudah usai atau selesai. Disebut gunungan karena bentuknya seperti gunung yang ujung atasnya meruncing. Gunungan ini dalam legendanya berisi mitos sangkan paraning dumadi, yaitu asal mulanya kehidupan ini dan disebut juga kayon. Gunungan merupakan simbol kehidupan, jadi setiap gambar yang berada di dalamnya melambangkan seluruh alam raya beserta isinya mulai dari manusia sampai dengan hewan serta hutan dan perlengkapannya. Gunungan dilihat dari segi bentuk segi lima, mempunyai makna bahwa segi lima itu lima waktu yang harus dilakukan oleh agama adapun bentuk gunungan meruncing ke atas itu melambangkan bahwa manusia hidup ini menuju yang di atas yaitu Allah SWT.
Setelah peneliti melakukan kajian, pengamatan ulang dari beberapa hasil penelitian dan tulisan yang sudah dilakukan di atas dan berdasarkan nara sumber tokoh pengrajin seni hias wuwung Mayong Lor (Ridwan dan Sunari), budayawan (Indra Trenggono, Sunarto, Bugis Wantara) dan seniman Jepara (Jatmiko), masyarakat umum dan pemerintah desa melalui sekretaris petinggi desa Mayong Lor. Juga informasi penting dari bidang Litbang Jepara (bapak Yurisman kepala Litbang Jepara) sebagian besar menyatakan bahwa wuwung dengan nuansa pecahan beling pasti memiliki maksud dan tujuan. Dan bagian seni hias wuwung Mayong Jepara yang diterapkan dalam rumah tradisional masyarakat memiliki bentuk yang indah dan kekhasan sebagai penciri rumah dari Jepara dan sekitarnya yang akrab disebut sebagai wuwung wayang. Keindahan yang tervisualisasi dalam bentuk seni hias wuwung dengan pecahan piring merupakan bentuk ekspresi seniman atau pengrajin sebagai masyarakat Jawa yang di dalamnya mengandung unsur filosofi syarat dengan makna.

Seni hias wuwung yang diterapkan pada molo rumah yaitu pada sisi atas atap merupakan bagian yang syarat dengan makna yang bertujuan pada doa dan pengharapan. Wuwung ini terdiri dari dua bagian yaitu bagian tengah yang disebut 
dengan istilah musthoko yang biasanya menghias bagian atap sebuah masjid atau musholla. Karena disebut musthoko tentu seni hias ini juga identik dengan bentuk mahkota yang sering digunakan oleh raja. Dari itu wuwung tengah ini juga disebut sebagai wuwung rojo. Juga bisa disebut sebagai bentuk gunungan yang dijadikan simbol sebagai bentuk alam raya jagat ciptaan Allah SWT. Yang kedua adalah bagian kanan dan kiri yang disebut sebagai wuwungan pengapit wuwungan gelung yang mirip seperti bentuk ukel ukiran Jepara dan bentuk gelung yang menghiasi kepala dari suatu tokoh wayang.

Jika mengambil inti sari dari sebutan wuwungan wayang yang akrab dalam kehidupan masyarakat Jawa maka penafsiran bentuk-bentuk seni hias wuwung Mayong Jepara jelas mengarah pada tokoh-tokoh kebaikan atau tokoh-tokoh pahlawan dalam membela kebenaran. Siapa tokoh pasti yang dijadikan sumber ide penciptaan wayang ini yang belum ditemukan dengan pasti. Semua masih interpretasi tetapi sangat mendukung dan mengarah pada tokoh-tokoh dalam dunia wayang yang memiliki jiwa dan kepribadian yang baik.

\section{KESIMPULAN}

Pandangan hidup masyarakat Jawa secara garis besar dapat diurai ke dalam beberapa arah pengungkapan, yaitu tentang kepercayaan yang mereka anut, pengetahuan, etika sosial, dan rasa estetika. Tradisi kejawen yang mengutamakan hidup berolah batin, menanamkan hal-hal spiritual dalam kehidupan sehari-hari. Adanya pengaruh agama Hindu-Budha dan pengaruh Islam yang kuat di daerah pesisir utara Jawa yang datang menambah khazanah hidup batin orang Jawa, memperhalus dan mempertinggi peradabannya. Walaupun demikian sifat khas Jawanya tidak hilang, bahkan unsur-unsur mistik Hindu-Budha berhasil di-Jawakan sehingga merasa benar-benar itu adalah milik asli leluhur Jawa.

Seni hias wuwung gerabah Desa Mayong Jepara merupakan produk budaya Jawa sebagai ungkapan rasa estetika. Aktivitas produksi membuat gerabah di Desa Mayong Jepara terutama produk seni hias wuwung gerabah ini diwariskan secara turun-tumurun oleh para pengrajin kepada anak-anaknya, sehingga keberlangsungannya tetap eksis sampai sekarang. Namun tidak dipungkiri perlu eksistensi dan perhatian khusus darai masyarakat penyangga dan dinas terkait untuk tetap memberikan support kepada pengarajin seni hias wuwung yang cantik ini agar tidak punah digerus perubahan konsep rumah modern yang cepat dan menghilangkan identitas bangunanbangunan bernuansa tradisi Jawa.

Seni hias wuwung gerabah Desa Mayong Jepara memiliki nilai seni dan ekonomi dimana keberadaannya sebagai warisan budaya masyarakat Jawa perlu dilestarikan. Dari segi fungsi ternyata seni hias wuwung memiliki fungsi aktif dan pasif. Fungsi aktif lebih dominan sebagai benda fungsi untuk menahan debu, air dan 
angin yang masuk ke dalam rumah serta berfungsi sebagai seni hias dan fungsi pasif dimana sebagian masyarakat Jawa masih mempercayai bahwa motif tertentu dari seni hias wuwung gerabah memiliki arti yang mengandung makna/tujuan.

Kegiatan membuat seni hias wuwung dengan teknik pecahan beling/piring, dapat dikatakan memiliki fungsi sosial yang berbentuk kolektif dengan bentuk yang sama. Fungsi sosial sebagai pengikat solidaritas masyarakat dan menjadi ciri kelompok komunal. Kegiatan membuat seni hias wuwung juga memiliki fungsi personal bagi pengrajinnya, tidak berbeda dengan seni murni lainnya secara personal sebagai penuangan ekspresi estetik pribadi senimannya. Dalam hal ini pengrajin seni hias wuwung gerabah Desa Mayong Jepara yang menuangkan ekpresinya pada produk gerabah pada seni hias wuwung dengan teknik tempel pecahan beling/piring yang mengikuti bentuk ukiran yang indah. Dengan harapan semoga seni hias wuwung Mayong Jepara tetap dapat dilestarikan dan dijaga regenerasi pengrajinnya agar keindahan seni yang memiliki ciri khas local genius tidak hilang begitu saja dan melekat kuat sebagai ciri budaya masyarakat Jepara sebagai bagian masyarakat yang berbudaya Jawa memperkuat budaya Indonesia.

\section{DAFTAR PUSTAKA}

Feldman, Edmund Burke, 1967, Art As Image and Idea, Prentice hall, Inc. Englewood Cliffs, New Jersey

Fischer, Joseph, 1994, The Folk Art of Java, Oxford University Press, Oxford, Singapore, New York, Kualalumpur

Gustami, SP, 2000, Seni Kerajinan Mebel Ukir Jepara, Kajian Estetik Melalui Pendekatan Multidisiplin, Kanisius, Yogyakarta.

2003, Metode Pendekatan dalam Kajian Seni Rupa, dalam Bunga Rampai Kajian Seni Rupa, dalam Kenangan Purnatugas Prof. Drs. Suwaji Bastomi, UNNES Press, Semarang 2007, Butir-Butir Mutiara Estetika Timur, Penerbit Prasista, Yogyakarta 2008, Nukilan Seni Ornamen Indonesia, Diterbitkan Jurusan Kriya, Fakultas Seni Rupa, Yogyakarta

Soesilo, 2002, Ajaran Kejawen, Philosofi dan Perilaku, AK Group, Yogyakarta

Hermanu, 2004, Seni Awang-awang, Arsitektur Jawa Lama, Bentara Budaya, Jakarta 
Herusatoto, Budiono, 2001, Simbolisme Dalam Budaya Jawa, Hanindita Graha Widia, Yogyakarta

Ismunandar, R, 1986, Joglo Arsitektur Rumah Tradisional Jawa,Penerbit Dahara Prize, Yogyakarta

Kristina, M.T, 2002, dalam Soesilo, Ajaran Kejawen, Philosofi dan Perilaku, AK Group, Yogyakarta

Kuntowijoyo, 1999, Budaya dan Masyarakat, Tiara Wacana, Yogyakarta

Moleong, Lexy J, 2004, Metodologi Penelitian Kualitatif, Penerbit PT Remaja Rosdakarya, Bandung

Mucthar, But, 1991, "Daya Cipta Bidang Kriya" dalam SENI, Jurnal Pengetahuan dan Penciptaan Seni, VII/01, BP ISI Yogyakarta

Mulder, D.C., 1970, Java Religie en Kunst: de Religie van Java, Amsterdam.

Nurhadi dkk, 1991, Komposisi dan Dinamika Perubahan Arsitektur Tradisional Yogyakarta, Makalah pada Sarasehan Arsitektur Tradisional Yogyakarta, Yogyakarta.

Ronald, Arya, 2005, Nilai-nilai Arsitektur Rumah Tradisional Jawa, Gadjah Mada University Press,Yogyakarta
Soedarsono, R.M, 1999, Metodologi Penelitian Seni Rupa dan Pertunjukan, Masyarakat Seni Pertunjukan Seni Indonesia, Bandung

Suwarno, 2007, Makna Simbolis Hiasan Wayangan Pada Atap rumah Tradisional Kudus, Jantra Jurnal Sejarah dan Budaya, Yogyakarta

Wibowo, H.J., 1987, Arsitektur Tradisional Daerah Istimewa Yogyakarta, Depdikbud, Yogyakarta.

Widada, dkk, 2001, Kamus Bahasa Jawa (Bausastra Jawa), Kanisius, Yogyakarta 